\title{
STRATEGiC DEVELOPMENT OF MARITIME RELATED INDUSTRIES: THE ROLE OF MARITIME CLUSTER RESEARCHES
}

\author{
Kaidi Nommela \& Kati Korbe Kaare
}
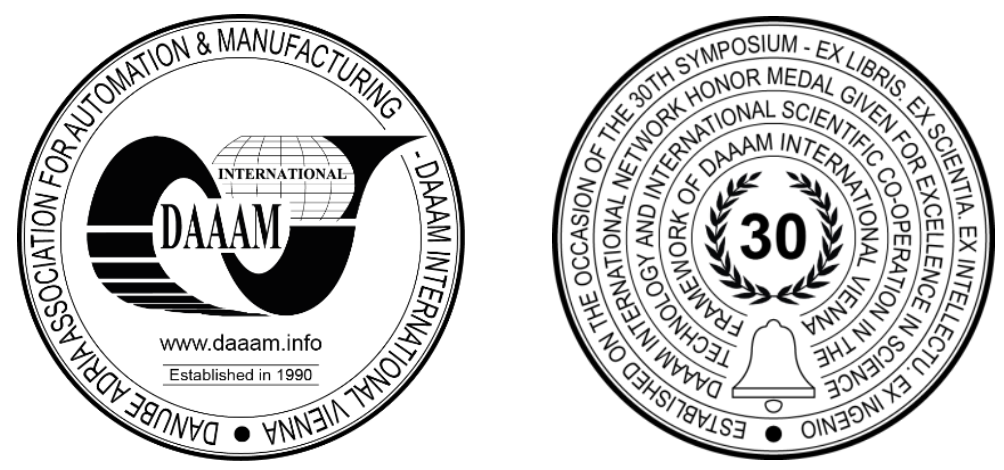

This Publication has to be referred as: Nommela, K[aidi] \& Korbe Kaare, K[ati] (2021). Strategic Development of Maritime Related Industries: The Role of Maritime Cluster Researches, Proceedings of the 32nd DAAAM International Symposium, pp.0500-0507, B. Katalinic (Ed.), Published by DAAAM International, ISBN 978-3-902734-33-4, ISSN 1726-9679, Vienna, Austria

DOI: $10.2507 / 32$ nd.daaam.proceedings.072

\begin{abstract}
Maritime clusters have an important impact on the development of regional industry. A well-functioning maritime cluster can enhance social and economic benefits and innovation on entire surrounding region. The European Union has placed cluster concept to the centre of region's strategic policy planning. Joint implementation of the maritime cluster concept is a way to meet challenges and achieve strategic development goals to increase the competitiveness of industries in a region. At the same time, cluster concept can have different meanings and there are different ways to analyze maritime cluster and it's positive impacts. Researches of maritime cluster related studies in the same area are using different approaches and frameworks. A coherent approach to cluster research has not yet been developed for the maritime sector; such research is incomparable and cannot be used as input for integrated policymaking. The aim of this study was to examine different approaches and monitoring frameworks that describe maritime clusters in the Baltic Sea Region which maritime activities make a significant contribution to the EU's maritime economy. The results of the study emphasize the need to develop a coherent framework of indicators to research and monitor maritime cluster performance as a basis for regional strategic policymaking.
\end{abstract}

Keywords: maritime industries; cluster performance; policymaking; Baltic Sea Region.

\section{Introduction}

Maritime sector have major impacts on the development of maritime related industries in the Baltic Sea Region (BSR) with considerable contribution to the entire economy of the region. Traditional maritime activities and emerging new areas are determining the regional competitiveness and international trade [1]. Maritime sectors offer a significant opportunity for economic growth and the development of the regional industries that rely in particular on cluster concept and innovation driven by green revolution and digital development. The digitalization process has changed the development of the economy through digital technologies affecting the business operations [2]. Enterprises together with regional policymakers are searching for opportunities to improve their performance in order to increase the competitive advantage of the region [3]. In addition, special empathizes in the BSR has also placed on sustainability goals, it is important to plan and be prepared for the future to support maritime sectors as a whole in the European Union (EU), incl. in the BSR [4]. 
The EU's Integrated Maritime Policy [5] sets strategic maritime objectives for the Union, i.a. maximizing the sustainable use of seas, building knowledge and innovation, improving the quality of life in coastal regions, etc. The Policy identifies maritime cluster as one of the most important instruments for achieving these goals. Although, maritime clusters in the EU are separate clusters, which often compete with each other, joint implementation of the maritime cluster concept is a way to meet the challenges and to increase the competitiveness of the region [6]. In addition, the concept of cluster in policymaking provides an opportunity to achieve jointly the global environmental goals for greener and more sustainable shipping sector as well as EU's target to develop prosperous maritime and related activities in an environmentally sustainable way.

According to Ketels [7], there are different ways to analyze maritime cluster and to explore its advantages and relatedness. Several authors have indicated that cluster concept can have different meanings and it may vary according to context of the study, economic sector, geographical scope, dimensions of a study, etc. [8], [9], [10]. Among cluster concept researchers, there is a well-known fact that common definition of a cluster has not yet been agreed [8], [11], [12], [13] and the debate on what constitutes a cluster is an on-going process in economic research [14]. Consequently, maritime cluster related studies of the same region use different approaches and frameworks for researching and monitoring maritime clusters and these studies are therefore incomparable and cannot be used as a basis for common policymaking to shape strategies and joint goals.

The aim of this study is to examine different methods and monitoring frameworks that describe maritime clusters in the BSR. This study identifies the need for a common methodology to maritime cluster research and monitoring frameworks that could help to achieve joint strategic goals and increase the competitiveness of the region through integrated maritime clusters and policymaking. A comparative analysis was carried out to establish the most relevant aspects and characteristics, which differentiate maritime cluster related studies. Analysis was applied to the maritime cluster related studies of seven Baltic Sea countries: Denmark, Estonia, Finland, Germany, Latvia, Lithuania and Sweden. The focus was to determine the following aspects of the studies revealed from literature review: the main aim of the study, applied cluster definition, study object, methods and main focus area of the study, and to identify differences in approaches and implementations of these aspects in the selected studies.

\section{Background - The concept of the maritime cluster in European Union's policymaking}

In the EU's economy, the implementation of a cluster concept has been an important way of analyzing economic developments and planning future strategies. However, the implementation of the concept is multifaceted, depending on the approach of implementation and the chosen economic theory. Different authors apply different theories in understanding the cluster concept, and the multidirectional knowledge and understanding has also reached to policymaking. The following is a brief background overview of the development and implementation of the maritime cluster concept in EU's policymaking.

In economics, clusters became known in the late 20th and early 21 st centuries, when globalization had peaked and economic theories introduced ways to promote geographically concentrated communities to strengthen regional development. So far, there is still no universally recognized standard definition of a cluster [8], [11], [12], [13] and the debate on what constitutes as a cluster is an on-going process [14]. One of the leading academic authorities in this area [12] Professor Michael E. Porter defined clusters as "geographically proximate group of interconnected companies and associated institutions in a particular field, linked by commonalities and complementarities. The geographic scope of clusters ranges from a region, a state, or even a single city to span nearby or neighbouring countries." [15] Since Porter, several authors has built the definition of a cluster on Porters' concept with own additions, regardless of the study field, aim etc.

The implementation of a cluster concept as a basis for policy has been supported and valued by international associations: the European Union [5], [16], [17]; the World Bank [18]; the Organisation for Economic Co-operation and Development [19], etc. After the EU launched an integrated policy approach to maritime related issues with a focus on cluster concept in the early 2000s, maritime cluster related researches have been carried out throughout the EU, including in the BSR, through various programs, projects and other actions. Although several joint cluster platforms have been set up, and several researches and projects have been carried out to study maritime clusters in the region, they all take a relatively different approach to the concept of a maritime cluster. As a result, there is no common methodology for researching and monitoring maritime clusters that can be used as a basis for creating political strategies. Instead, the research process starts each time from the beginning according to a specific goal, and leads to single-purpose work.

The concept of a cluster first appeared in EU's maritime policy documents in the early 2000s. The European Commission's (EC) Green Paper on towards a future Maritime Policy for the Union (2006) identified clustering as one way to increase the competitiveness of maritime sector, given its high degree of interaction [20]. The Paper emphasized the need for intra-sectoral knowledge sharing, joint research and innovation activities, harmonization of education and training, sharing of innovative technologies and methods, and joint marketing and advertising activities, especially in sectors with a complex supply chain such as logistics and maritime sector. The Integrated Maritime Policy Document (2007) placed maritime cluster at the centre of EU's maritime policy [5]. The Policy encouraged the creation of crosssectoral clusters and regional maritime centres of excellence and promoted the creation of European network of maritime clusters. The EC Staff Working Document on Maritime Clusters (2007) emphasized the need to integrate regional and national clusters with maritime and environmental aspects in order to contribute better quality and higher standards of European maritime products and services [16]. 
In 2009, the EC compiled an overview of European maritime clusters with the aim of gathering information on the size, specialization and focus of maritime sectors or clusters in the EU [21]. The paper defined cluster as a part of the maritime sector or region, which was divided into the traditional maritime sector, coastal tourism and recreational activities, and fisheries. This paper highlighted the need to analyze cluster policy and the success of the sector to provide an overview of how the implemented cluster policy has affected the development of the maritime sector. Since this project, the preparation of maritime cluster analysis became popular in the EU Member States, incl. in the BSR countries, although a number of different approaches were used.

The EU's first Smart Guide to Cluster Policy [22] was issued in 2016. The Guide explained the definition of clusters, the economic relevance of clusters and cluster policy, the process of creating a cluster policy, possibilities for monitoring and evaluation of cluster policy, etc. The Guide defined cluster as "concentration of economic activities in groups of related industries in a specific location that are connected through multiple linkages and spill-overs" and highlighted five main characteristics of a cluster: critical mass, related industries, location, linkages and the fact that vast majority of cluster cases are not 'created' [22]. Although the Guide covered all the necessary topics related to cluster policy, it did not contain precise instructions for identifying the existence and the performance of a cluster, but referred instead to the database of the European Cluster Observatory [23], where e.g. only 25 maritime related institutions from Estonia are represented (as of February 2021).

The EU's new Smart Guide to cluster policy was issued in 2020 with the focus on monitoring and evaluating a cluster policy [24]. This Guide defined cluster using Porter's [25] definition: "geographic concentrations of interconnected companies, specialized suppliers, service providers, firms in related industries, and associated institutions ... in particular fields that compete but also cooperate". The Guide emphasized the complex system of clusters, which rely on formal and non-formal interactions and the multiple variations of cluster policy forms, and highlighted the fact, there is no simple guide to monitor and evaluate cluster policies and each situation needs separate guidance how to deal with challenges in different scenarios [24].

The concept of cluster entered the European maritime policy documents in the early 2000s and since then, its implementation has taken place in different directions. Although the EU has encouraged Member States for the last twenty years to implement the cluster theory and concept in policymaking, different approaches and methodologies have made the process diverse and the results incomparable. The same has happened in the Baltic Sea region, where regional specificities and joint challenges need a coherent approach to regional policymaking, supported by the integrity of the implementation of the cluster concept.

\subsection{The Baltic Sea Region's maritime sector in the EU}

The Baltic Sea is located in the northern part of Europe and it is one of the densest shipping areas in the world, with around 2,000 ships operating at the same time [26]. The EU's countries around the Baltic Sea are Sweden, Finland, Estonia, Latvia, Lithuania, Poland, Germany and Denmark (see Figure 1, the gross weight of Germany's goods includes only the Baltic Sea part). There are more than 400 seaports on the Baltic Sea, of which more than 90 are of international importance.

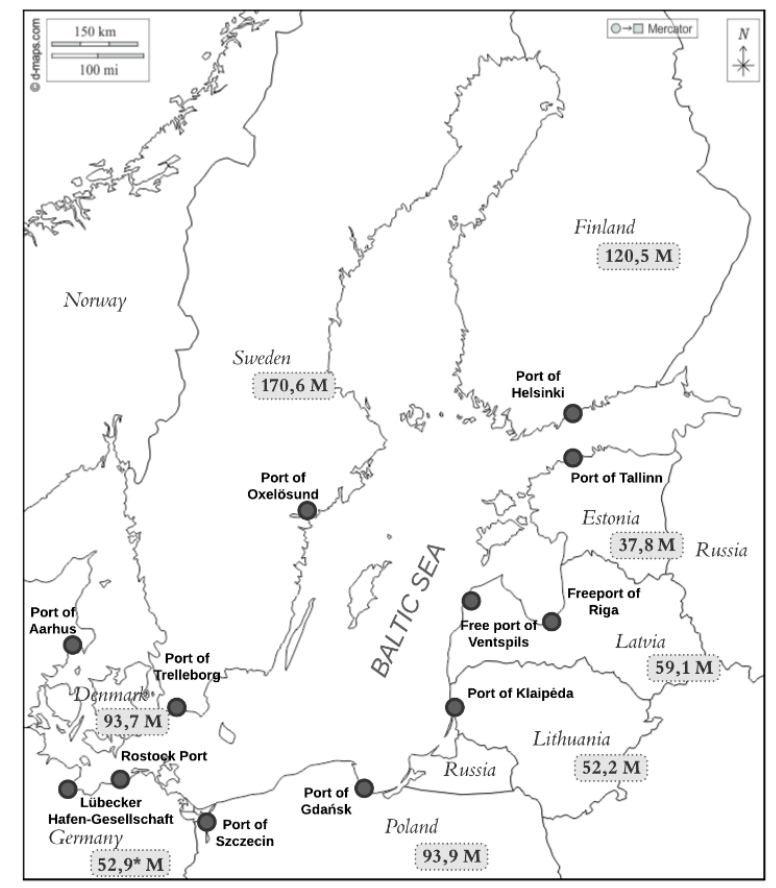

Fig. 1. Map of the Baltic Sea Region with states, major ports and gross weight of goods handled in all ports in 2019 (million tons). Source: d-maps.com [27], Eurostat [28], amended by the authors. 
Shipping and other related maritime activities are essential for the BSR development and international trade [1]. The development of the maritime sector in the BSR has always been an important part of the entire EU maritime sector. The BSR is a considerable cargo transit corridor for north-south and east-west traffic. In 2019, the total gross weight of goods handled in BSR main ports was over 586 million tons, which accounted almost $15 \%$ of all European cargo traffic through seaports in the same year. Compared to previous ten years (2010-2019), the BSR share of cargo traffic through the main seaports has remained stable (see Figure 2) [29]. In 2019, the total number of passengers transported to and from BSR main ports (both national and international) was over 100 million people, which accounted for $42 \%$ of all European passenger traffic through seaports in the same year. Compared to previous ten years (2010-2019), the BSR share of passenger traffic through the main seaports has also remained stable (see Figure 2) [30].

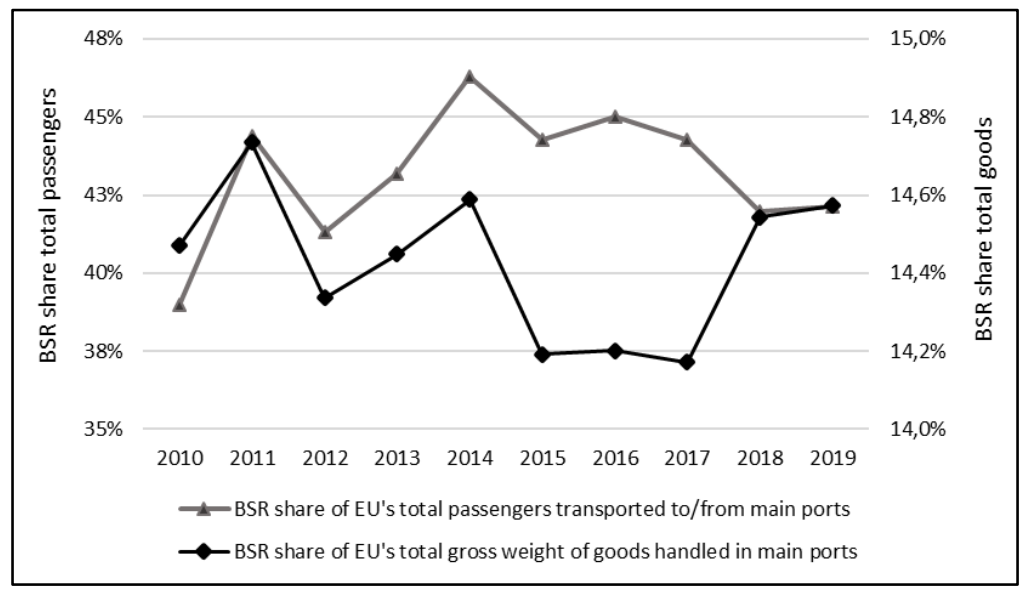

Fig. 2. BSR share of EU's total goods and passengers transported in main ports in $2010-2019$ Source: Eurostat [29], [30], compiled by the authors

The BSR maritime sector accounts for a significant share of EU maritime affairs. Therefore, it is important that EU's policymaking process takes into account the challenges and development opportunities of the region. The application of the cluster concept in regional policymaking can be of greater value in regions where the development is affected by similar trends. Consequently, it is necessary to identify different methods of defining the existence and describing the current state and performance of maritime clusters in the BSR to increase the competitiveness through integrated maritime clusters and policymaking.

\section{Methods}

The research design of this work is based on the premise that there are several possibilities and different ways to approach a research of maritime cluster, depending on the research object, theme, study objective, methodology, etc. However, to achieve the goals of a coherent policy and to increase the competitiveness of the region, a common approach and monitoring framework to maritime clusters is important. In this work, we compare maritime cluster related studies conducted in the BSR in order to examine different approaches and explore the need for a common methodology to maritime cluster research, which can be a basis for policymaking in maritime sector. Nine maritime cluster related studies were included to this analysis. The maritime clusters related studies in the BSR selected for this analysis are:

- Competencies in the Danish Maritime Cluster: A benchmarking-analysis [31],

- Maritime Cluster Research of Estonia [32],

- The Finnish Maritime Cluster 2004 [33],

- The Finnish Maritime Cluster 2008 [34],

- The Finnish maritime cluster towards the 2020s [35],

- A Differentiation Framework for Maritime Clusters: Comparisons across Europe [36],

- Development of the Latvian Maritime Policy; A Maritime Cluster Approach [37],

- Lithuanian maritime sector's clustering economic impact evaluation [38],

- Maritime Clusters in Västra Götaland [39].

Based on literature review of cluster economic concept, a comparative analysis framework to distinguish main differences between selected maritime cluster related studies was created. A combination of dimension of cluster research was used for the analysis. This framework included different comparison dimensions: 1. main aim; 2. cluster definition; 3. study object; 4. main methods; 5 . main focus area of the study. The last contained main characteristics of a cluster proposed by different authors in literature review: workforce (workforce structure and needs); relationships between members; competition; competitiveness; geographical scope; geographical orientation; structure of members; number of members [15], [25], [40], [41]. 


\section{Comparative analysis of maritime cluster related studies}

A comparative analysis was carried out in order to examine different approaches and monitoring frameworks used in maritime clusters related studies in the BSR. The aim was to identify the main differences and links between the used approaches and the need for a common methodology to maritime cluster research and monitoring frameworks that could be valuable input to policymaking and evaluation in the region. A comparative analysis allows to find out differences in approaches across the main dimensions of cluster analysis and thus explain the impact of the used approaches on the results of the researches. Overview of the results of the comparative analysis is shown in the following table (see Table 1).

\begin{tabular}{|c|c|}
\hline $\begin{array}{l}\text { Comparison } \\
\text { dimensions }\end{array}$ & Differences between maritime cluster related studies \\
\hline Main aim & $\begin{array}{l}\text { Different in all studies, incl.: } \\
\text { - describe the current state and extract main characteristics; } \\
\text { - assess future prospects and growth areas, evaluate the economic impact of the cluster; } \\
\text { - outline a strategy or plan to further developments of the cluster; } \\
\text { - compare the cluster with international maritime clusters, define maritime cluster networks, ensure } \\
\text { the continuity of research. }\end{array}$ \\
\hline $\begin{array}{c}\text { Cluster } \\
\text { definition }\end{array}$ & $\begin{array}{l}\text { - Porter's definition }(1998,1999) \text {; } \\
\text { - authors' own definition (mostly, based on different theories and authors). }\end{array}$ \\
\hline Study object & $\begin{array}{l}\text { - In all studies: shipping and shipping related areas, maritime industry (incl. shipbuilding and repair, } \\
\text { equipment industry), ports and port operators; } \\
\text { - in most studies: maritime related services (transport services, companies related to shipping, } \\
\text { maritime logistics, classification institutions, finance and insurance, etc.), public sector } \\
\text { (authorities, education, science); } \\
\text { - in few studies: fishing and aquaculture, maritime tourism and recreation, offshore technology and } \\
\text { marine energy, maritime construction, blue (marine) biotechnology. }\end{array}$ \\
\hline $\begin{array}{l}\text { Main } \\
\text { methods }\end{array}$ & $\begin{array}{l}\text { - Literature review, incl. internet research, reports, books and scientific articles; } \\
\text { - quantitative analysis of maritime related companies' data, and qualitative analysis, incl. interviews } \\
\text { with actors, workshops, seminars, etc.; } \\
\text { - benchmarking-analysis. }\end{array}$ \\
\hline $\begin{array}{l}\text { Main focus } \\
\text { area }\end{array}$ & $\begin{array}{l}\text { - In most studies: quantitative overview of the cluster, incl. contribution to national economy, } \\
\text { number of employees, turnover, number of ships, etc.; } \\
\text { - in few studies: current state and overview of the cluster, incl. historic overview, development } \\
\text { prospects, future opportunities, growth prospects of the cluster. }\end{array}$ \\
\hline
\end{tabular}

Table 1. Overview of the results of the comparative analysis

All analysed studies had different main aims and focus in certain respects. Majority of studies main aim was to study and describe the current state of maritime cluster in the region based on an overall overview or focusing on specific characteristics. Describing the current situation was generally a common first step in examining a cluster. Multiple studies focused on identifying future possibilities and prospects and providing an analysis for the future growth areas. Other studies were compiled with the aim to outline a strategy or to initiate an action plan for further development strategy or maritime policy. Fewer studies were conducted to describe and evaluate the economic and social impact or value of a cluster. Least studies were conducted to compare maritime cluster of a region with international maritime clusters, to define maritime cluster networks or to ensure the continuity of research (i.e. were a follow-up research to previous cluster researchers).

In defining the cluster, the analysed studies used mainly two approaches: 1. the definitions issued by M. E. Porter in the late 1990s; 2. the authors formulated an appropriate definition themselves (usually, based on different theories and authors). The authors defined cluster mainly as a unit or concentrations of companies that uses maritime related knowhow and that interaction are proven to produce advantages. Other authors included to the definition other actors (in addition to companies), such as public authorities, organisations and research institutes. One study defined cluster within a specific regional area, and another defined cluster as geographically concentrated economic activities that are interconnected. As a result, the interpretation of a cluster varies widely in different studies.

Traditional maritime areas have been included to the research object in all analysed studies. These traditional areas include shipping with related fields, ports and port operators and maritime industry, such as shipbuilding and ship repair and marine equipment industry. Most studies also considered as a research object maritime related services, such as maritime logistics, transport services, classification institutions, finance and insurance, etc. Half of the studies included to the research object public sector (authorities, education and science institutions), fishing and aquaculture, maritime tourism and recreation and offshore technology, incl. marine energy. The inclusion of the latter depended in particular on the development of the sector in a specific region. Only few studies included maritime construction and marine (blue) biotechnology to the research object. 
The level of description of the research methodology differed in all analysed studies. Most studies referred to literature review and different quantitative and qualitative methods as main data collection methods. The sources of literature review were mainly internet based, reports and scientific literature. Economic data from companies were mainly described as the source of quantitative analysis and interviews with actors and workshops as the source of qualitative analysis. Some studies mentioned benchmarking as the main method of analysis, but the majority did not mention any specific method.

The main focus areas of the studies were also different and depended mostly on the main aim of the study. In most cases, the focus area was a descriptive overview of the current state and historic development of a cluster, or quantitative overview of a cluster's contribution to the national economy, incl. number of members, number of employees, total turnover, number of ships, etc. Mostly used indicators to analyse focus areas were geographical scope and competitiveness of a cluster, which was generally presented in a descriptive way. Workforce and geographical orientation were also used as analysis indicators, but in different level of detail. Relationships between members, structure and the concept of intracluster competition was the least analysed indicators in these studies.

The comparison of maritime cluster related studies of the BSR countries showed that there are different approaches to maritime cluster research and monitoring frameworks depending on the main aim of the study, applied cluster definition, research object, methods and focus areas. Majority of studies were carried out to describe the current state of maritime cluster in the region based on an overall overview. Other studies were designed to explore a specific narrow topic. In defining the concept of a cluster, the Porter's definitions or the authors' own interpretation of various explanations of the concept were mainly used. Studies that used Porter's definition took more similar approach to the cluster concept, but the studies that used the authors' own definitions had broader difference in the interpretation of the concept. The research methods varied greatly and did not depend on the purpose or focus of the study. At the same time, the focus area and analysed characteristics depended on the main topic of the study. Geographical scope and competitiveness of a cluster were the most analysed indicators, although they were examined in different ways and mainly descriptively.

All these differences in the approaches and frameworks hinder the use of cluster research in international regional policy-making. The diverse application of the aspects of cluster research described in economic theory makes the results of cluster research incomparable and, consequently, unsuitable input for joint policymaking in the region.

\section{Conclusion}

In the BSR, maritime clusters have an important impact on the development of regional industry. Although, clusters often compete with each other, they also face similar challenges and opportunities at the same time, which can be addressed through joint strategic policymaking. The EU has set common policy goals for the region to enhance the interaction of maritime clusters and policymaking. Although a number of maritime cluster studies have been carried out in the BSR over the years, these studies have used multiple theoretical and methodological approaches, as there is no right or wrong way to apply cluster concept. The results of this study revealed that there are different approaches and monitoring frameworks to maritime cluster research in the region and that these researches cannot be considered as comparable for policymaking. The aim of most researches was to study and describe the current state of maritime cluster in the region based on an overall overview or focusing on specific characteristics. Some studies also had the goal to identify future possibilities and growth areas of the maritime cluster.

As the main purpose of the studies differed, so did the applied cluster definitions, methods and focus areas and analysed characteristics. Many authors defined cluster with Porter's definition from the late 1990s or used their own interpretations of different definitions. Studies that used similar definition (e.g. Porter's definition) took more similar approach to the cluster concept, but the studies that used own interpretations had broader difference. The focus areas of the studies and analysed characteristics mostly depended on the purpose of the work. Although literature review highlights main characteristics describing a cluster, the analysed studies gave an overview of those characteristics that were related to the purpose of their work and did not address other characteristics of a cluster. As a result, there was a lack of a comprehensive understanding of the region's maritime clusters on the basis of cluster characteristics.

One of the dimensions that were similar in most analysed studies was the object of research that depended on the geographical location of a cluster or the national economy rather than on the research approach. As maritime sector is one of the traditional sectors in coastal nations' economy, which covers areas of activity with a long history, thus maritime cluster related studies often examine similar maritime activities as a research object. Most of the studies covered maritime activities, such as shipping, ports and port operators, maritime industry (incl. shipbuilding and ship repair) and maritime related services (incl. maritime logistics, transport services, classification institutions, finance and insurance). Less was studied public sector (incl. authorities, education and science institutions), fishing and aquaculture, maritime tourism and recreation and offshore technology (i.a. marine energy) and marine (blue) biotechnology.

Several joint cluster platforms have been set up, and multiple researches and projects have been carried out to research maritime clusters in the EU and in the BSR. However, due to the wide range of interpretations of the cluster concept, different approaches are still in use. This makes it difficult to implement the cluster concept and its potential benefits and opportunities in policymaking due to the lack of a comprehensive understanding of the current situation and future opportunities of the maritime clusters in the region. Consequently, the authors of this work emphasize the need for a coherent approach to maritime cluster research in the regions where common strategic policy objectives are set and common challenges and opportunities lie ahead. 
Although the results of this work have shown that it is necessary to create a common approach and framework for conducting maritime cluster related studies to ensure their comparability, the main aim and focus of the studies are always the decision of the researchers and/or clients. A common framework would not prevent the different aims and focus themes of the studies, but would ensure the comparability of the maritime cluster dimensions and research components, their use as input for policymaking and the possibility of follow-up researches.

As a follow-up to this study, the authors plan to carry out a comparative analysis of the region's maritime clusters based on previously developed monitoring frameworks in order to compare the results of different analysis techniques. Such analysis would provide necessary and comparative overview of the BSR maritime clusters and serve as a basis for identifying competitive advantages of clusters, development trends and future scenarios affecting the region, which will be an important input for cluster policymaking. In addition, the authors also have started to develop a common framework for defining and identifying maritime clusters, which can be used as a basis for analyzing maritime related industrial clusters.

\section{References}

[1] Matczak, M. (2018). Exploring the future of shipping in the Baltic Sea. Baltic Lines, Quo Vadis. Coherent Linear Infrastructures in Baltic Maritime Spatial Plans. Available from: https://vasab.org/wpcontent/uploads/2018/08/20180730_FutureShippingQuoVadis.pdf Accessed: 2021-05-20

[2] Kokolek, N., Jakovic, B. \& Curlin, T. (2019). Digital Knowledge and Skills - Key Factors for Digital Transformation, Proceedings of the 30th DAAAM International Symposium, pp.0046-0053, B. Katalinic (Ed.), Published by DAAAM International, ISBN 978-3-902734-22-8, ISSN 1726-9679, Vienna, Austria. DOI: 10.2507/30th.daaam.proceedings.006

[3] Stojkic, Z. \& Bosnjak, I. (2019). An Overview of Performance Measurement Methods in SMEs, Proceedings of the 30th DAAAM International Symposium, pp.0518-0524, B. Katalinic (Ed.), Published by DAAAM International, ISBN 978-3-902734-22-8, ISSN 1726-9679, Vienna, Austria. DOI: 10.2507/30th.daaam.proceedings.070

[4] Routa, T. (2016). Evolution of the maritime cluster in a changing world. The maritime cluster in the Baltic Sea region and beyond. BSR Policy Briefing 1/2016, Centrum Balticum Foundation. ISBN: ISSN 2342-3153

[5] European Commission. (2007a). Communication from the Commission to the European Parliament, the Council, the European Economic and Social Committee and the Committee of the Regions. An Integrated Maritime Policy for the European Union Brussels, 10.10.2007 COM(2007) 575 final

[6] SmartComp. (2012). Maritime cluster analysis on the Central Baltic region. SmartComp Research Report No 1, University of Turku, $2012 . \quad$ December 20 from: https://www.utu.fi/sites/default/files/media/PEI_SmartComp_ResearchReport1.pdf Accessed: 2021-03-15

[7] Ketels, C. (2017). Cluster Mapping as a Tool for Development. Institute for Strategy and Competitiveness. Harvard Business School. Available from: https://www.hbs.edu/ris/Publication\%20Files/Cluster\%20Mapping\%20as\%20a\%20Tool\%20for\%20Development \%20_\%20report_ISC\%20WP\%20version\%2010-10-17_c46d2cf1-41ed-43c0-bfd8-932957a4ceda.pdf Accessed: 2021-03-21

[8] Cortright, J. (2006). Making Sense of Clusters: Regional Competitiveness and Economic Development. A Discussion Paper Prepared for the The Brookings Institution Metropolitan Policy Program. The Brookings Institution.

[9] Brett, V. \& Roe, M. (2010). The potential for the clustering of the maritime transport sector in the Greater Dublin Region. Maritime Policy \& Management, 37:1, 1-16. DOI: 10.1080/03088830903461126

[10] Pinto, H., Cruz, A. R., Combe, C. (2015). Cooperation and the emergence of maritime clusters in the Atlantic: Analysis and implications of innovation and human capital for blue growth. Marine Policy, Volume 57, July 2015, Pages 167-177. Available from: https://doi.org/10.1016/j.marpol.2015.03.029 Accessed: 2021-02-17

[11] Deloreux, D., Shearmur, R. (2009). Maritime clusters in diverse regional contexts: The case of Canada. Marine Policy 33 (2009) 520-527. DOI: 10.1016/j.marpol.2008.12.001

[12] Han, C-H. (2006). Comparative Analysis on World's Major Maritime Cluster. The Journal of Maritime Business, No.81, pp. 89-114 Dec 2006

[13] Lagoudis, I., Madentzoglou, E. M., Theotokas, I. N., Yip, T. L. (2019). Maritime Cluster Attractiveness Index. Maritime Business Review, vol. 4 No. 2, 2019 pp. 169-189. DOI: 10.1108/MABR-11-2018-0044

[14] Andersson, T., Schwaag-Serger, S., Sörvik, J., Hansson, E. W. (2004). The Cluster Policies Whitebook. IKED International Organisation for Knowledge Economy and Enterprise Development, Holmbergs August 2004

[15] Porter. M. E. (2000). Location, Competition, and Economic Development: Local Clusters in a Global Economy. Economic Development Quarterly 14:15-34. DOI: 10.1177/089124240001400105

[16] European Commission. (2007b). Commission Staff Working Document, Maritime Clusters. Brussels, 17.10.2007 SEC(2007) 1406

[17] European Union. (2010). Clusters and clustering policy: a guide for regional and local policy makers. INNO Germany AG, ISBN: 978-92-895-0506-2

[18] International Trade Department. (2009). Clusters for Competitiveness. A Practical Guide \& Policy Implications for Developing Cluster Initiatives. The World Bank, February 2009 
[19] OECD (2005). Business Clusters: Promoting Enterprise in Central and Eastern Europe. OECD Local Economic and Employment Development (LEED) Programme, august 2005, ISBN: 9264007105

[20] European Commission. (2006). Green Paper. Towards a future Maritime Policy for the Union: A European vision for the oceans and seas. Brussels, 7.6.2006 COM(2006) 275 final Volume II - ANNEX

[21] European Communities. (2009). The role of maritime clusters to enhance the strength and development in European maritime sectors, executive summary. Office for Official Publications of the European Communities, Available from: https://op.europa.eu/en/publication-detail/-/publication/2d594b8b-10fa-441f-8d81-7afea1dfca47 Accessed: 2021-03-05

[22] European Commission. (2016). Smart Guide to Cluster Policy. Directorate-General for Internal Market, Industry, Entrepreneurship and SMEs. DOI: 10.2873/48105

[23] European Cluster Observatory. (2021). Cluster Observatory, data. Available from: http://www.clusterobservatory.eu/data Accessed: 2021-02-10

[24] European Union. (2020). Smart Guide to cluster policy monitoring and evaluation. European Commission's Directorate-General for Internal Market, Industry, Entrepreneurship and SMEs, COSME programme, Publication Office of the European Union

[25] Porter, M. E. (1998). Clusters and the New Economics of Competition. Harvard Business Review, NovemberDecember 1998

[26] Aro, E., Rytter, N. G. M., Itälinna, T. (2020). Maritime industry processes in the Baltic Sea Region, Synthesis of eco-inefficiencies and the potential of digital technologies for solving them. ECOPRODIGI Research Report 2020, Turku School of Economics. Available from: https://ecoprodigi.eu/wp-content/uploads/2020/02/ECOPRODIGIResearch-Report-1-2020-final.pdf Accessed: 2021-03-05

[27] d-map.com. (2021). Baltic Sea map. Retrieved from: https://www.d-maps.com/pays.php?num_pay=182\&lang=en Accessed: 2021-05-11

[28] Eurostat. (2019a). Gross weight of goods handled in all ports by direction - annual data. Retrieved 3.07.2021, European Commission. Available from: https://ec.europa.eu/eurostat/databrowser/view/mar_go_aa/default/table?lang=en Accessed: 2021-04-16

[29] Eurostat. (2019b). Gross weight of goods handled in main ports by direction and type of cargo - quarterly data. Retrieved 25.05.2021, from European Commission. Available from: https://ec.europa.eu/eurostat/databrowser/view/MAR_GO_QMC_custom_992283/default/table?lang=en Accessed: 2021-04-16

[30] Eurostat. (2019c). Passengers transported to/from main ports by direction and type of traffic (national and international) - quarterly data. Retrieved 18.05.2021, European Commission. Available from: https://ec.europa.eu/eurostat/databrowser/view/mar_pa_qm/default/table?lang=en Accessed: 2021-04-16

[31] Gammelgaard, B., Sornn-Friese, H., Hansen, J., Jessen, M., Larsen, M. (2013). Competencies in the Danish Maritime Cluster: A benchmarking-analysis. Danish Maritime Cluster (DKMK), ISBN: 978-87-996049-1-3

[32] Portsmuth, R., Hunt, T., Terk, E., Nõmmela, K., Hartikainen, A. (2011). Maritime Cluster Research (Merenduse klasteruuring). Eesti Mereakadeemia toimetised nr 12, Estonian Maritime Academy, ISSN: 1736-207

[33] Viitanen, M., Karvonen, T., Vaitse, J., Hernesniemi, H. (2003). The Finnish Maritime Cluster. Technology Review 145/2003, National Technology Agency

[34] Karvonen, T., Vaitse, J., Hernesniemi, H. (2008). Finland Maritime Cluster 2008 (Suomen meriklusteri 2008). Tekesin katsaus 226/2008, Tekes 2008, ISSN: 1239-758X

[35] Karvonen, T., Grönlund, M., Jokinen, L., Mäkeläinen, K., Oinas, P., Pönni, V., Ranti, T., Saarni, J., Saurama, A. (2016). Finnish maritime cluster towards the 2020s (Suomen meriklusteri kohti 2020-lukua). Ministry of Economic Affairs and Employment, ISBN: 978-952-327-127-2

[36] Monteiro, P., de Noronha, T., Neto, P. (2013). A Differentiation Framework for Maritime Clusters: Comparisons across Europe. Sustainability 2013, 5, 4076-4105. DOI: 10.3390/su5094076

[37] Gailitis, R., Jansen, M. (2012). Development of the Latvian Maritime Policy; A Maritime Cluster Approach. International Journal on Marine Navigation and Safety of Sea Transportation, volume 6, number 2. DOI: $10.1201 / \mathrm{b} 11347-19$

[38] Viederyte, R. . (2014). Lithuanian maritime sector's clustering economic impact evaluation. Procedia - Social and Behavioral Sciences 156 (2014) 292 - 297, 19th International Scientific Conference; Economics and Management 2014, ICEM 2014, 23-25

[39] Wenblad, A., Lindegarth, S., Hanning, A. (2012). Maritime Clusters in Västra Götaland. Gothenburg and Tjärnö in October 2012, Available from: https://scanbaltbusiness.com/wp-content/uploads/2013/02/Maritime-ClustersV\%C3\%A4stra-G\%C3\%B6taland2.pdf Accessed: 2021-03-15

[40] Koschatzky, K., Lo, V. (2007). Methodological framework for cluster analyses. Fraunhofer Institute for Systems and Innovation Research ISI. Karlsruhe 2007, ISSN: 1438-9843

[41] Boja, C. (2011). Clusters Models, Factors and Characteristics. International Journal of Economic Practices and Theories, Vol. 1, No. 1, 2011 